\title{
Color-coded Imaging of the Circulating Tumor Cell Microenvironment
}

\author{
TOMOYUKI SATAKE ${ }^{1}$, ATSUSHI SUETSUGU ${ }^{1,2,3}$, MIKI NAKAMURA ${ }^{1}$, TAKAHIRO KUNISADA ${ }^{1}$, \\ MASAHITO SHIMIZU $^{1}$, SHIGETOYO SAJI ${ }^{1}$, HISATAKA MORIWAKI ${ }^{1}$ and ROBERT M. HOFFMAN ${ }^{2,3}$ \\ ${ }^{1}$ Gifu University Graduate School of Medicine, Gifu, Japan; \\ ${ }^{2}$ AntiCancer, Inc., San Diego, CA, U.S.A.; \\ ${ }^{3}$ Department of Surgery, University of California, San Diego, CA, U.S.A.
}

\begin{abstract}
Background/Aim: Circulating tumor cells (CTCs) may initiate metastasis. Some studies show that the number of CTCs and existence of CTC clusters can be prognostic. In the present study, our color-coded imaging nude mouse model of metastatic lymphoma was utilized to investigate the microenvironment of CTC clusters using fluorescent-protein imaging. Materials and Methods: EL-4 mouse lymphoma cells expressing red fluorescent protein $(R F P)$ were injected into the spleen of transgenic C57B/6-green fluorescent protein (GFP) mice. Three weeks later, the number of CTCs and CTC clusters both in heart blood and portal blood were quantified and characterized using confocal microscopy for color-coded imaging. Results: There was no significant difference in the number of CTCs between heart and portal blood. CTC clusters comprised $8.8 \%$ of CTCs, determined by color-coded imaging. Heterotypic CTC clusters containing other types of cells were distinguishable from homotypic CTCs. Heterotypic CTC clusters comprising cancer cells and fibroblasts were more rare than homotypic ones. Heterotypic CTC clusters with fibroblasts were observed only in portal blood, not in heart blood. Conclusion: CTCs can have variable properties depending on the blood source. CTCs can form clusters, which may contain fibroblast that may play a role in promoting CTC metastasis. Our results demonstrate the concept of the CTC microenvironment $(C M E)$, which may play a critical role in CTC behavior, including of metastasis.
\end{abstract}

Correspondence to: Atsushi Suetsugu, MD, Ph.D., Department of Gastroenterology, Gifu University Graduate School of Medicine, Gifu, Japan, 1-1 Yanagido, Gifu 501-1194, Japan. Tel: +81 582306308, Fax: +81582306310,e-mail: asue@gifu-u.ac.jp; Robert M. Hoffman, Ph.D., Anticancer, Inc., 7917 Ostrow Street, San Diego, CA 92111, U.S.A. Tel: +1 858642555, Fax: +1 8582684175, e-mail: all@anticancer.com

Key Words: Malignant lymphoma, circulating tumor cells, CTC clusters, fibroblasts, green fluorescent protein, red fluorescent protein, color-coded imaging, microenvironment.
Circulating tumor cells (CTCs) were discovered in the 19th century (1). CTCs may play a role in metastasis. The number of CTCs has a significant relationship with poor prognosis of patients with cancer. For example, the presence of CTCs indicates a poor prognosis in malignant lymphoma (2). CTCs collected from different vascular sites may have different characteristics (3). In addition, CTC clusters may have higher metastatic potential (4-12).

We previously developed a syngeneic mouse model of malignant lymphoma using murine EL-4 lymphoma cells expressing red fluorescent protein (RFP) implanted in transgenic mice expressing green fluorescent protein (GFP) (13). The dual-color malignant lymphoma model was used for color-coded imaging of the tumor microenvironment, allowing identification of the different cell types associated with the lymphoma cells at primary and metastatic sites (13).

Fibroblasts have been observed to be possibly associated with CTCs and may play a role in the metastatic potential of CTCs (14).

In the present study, using the EL4 mouse model of metastatic lymphoma, the CTC microenvironment was compared between heart blood and portal blood and the components of CTC clusters were determined by color-coded imaging.

\section{Materials and Methods}

Cell line and culture conditions. EL4 mouse malignant lymphoma cells were engineered to stably express RFP as previously reported $(13,15)$. The cells were maintained in RPMI 1640 medium (GibcoBRL, Grand island, NY, USA) supplemented with $10 \%$ heatinactivated fetal bovine serum and $1 \%$ penicillin and streptomycin (Gibco-BRL). The cells were cultured in a humidified atmosphere containing $5 \% \mathrm{CO}_{2}$ at $37^{\circ} \mathrm{C}$.

GFP transgenic mice. Transgenic C57B/6-GFP mice were obtained from the Research Institute for Microbial Diseases (Osaka University, Osaka, Japan). The C57B/6 mice expressed the Aequorea victoria GFP under the control of chicken $\beta$-actin promoter and cytomegalovirus enhancer. 

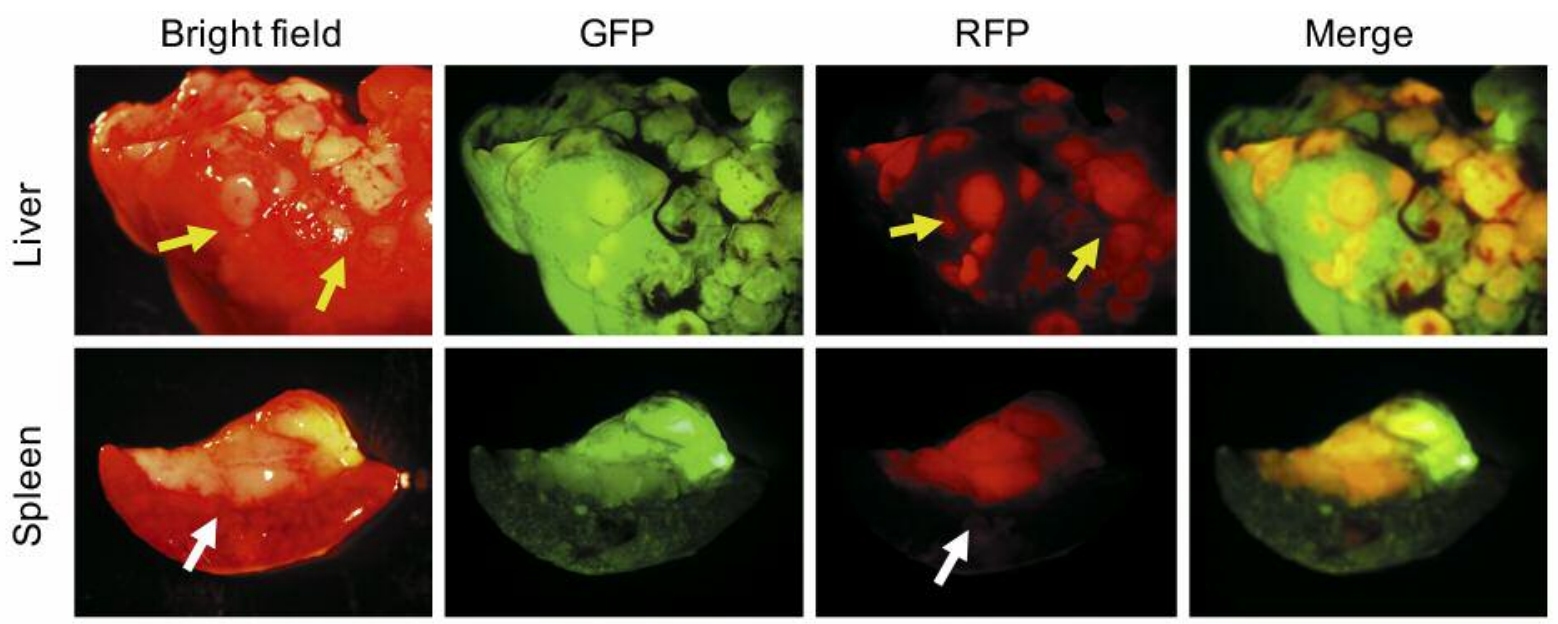

Figure 1. Experimental model of metastasis of EL4 malignant lymphoma. Bright-field and fluorescence images of liver and spleen. Yellow arrows indicate liver metastases. White arrow indicates primary tumor in the spleen. Images were obtained with SZX7 microscope. Bar=2 mm.

Mice. All experiments were conducted in accordance with the institutional guidelines of Gifu University, Gifu, Japan, and approved by the animal research committee and the committee on living modified organisms of Gifu University (approval number 26-37). In order to minimize any suffering of the animals, anesthesia and analgesics were used for all surgical experiments. Animals were anesthetized by subcutaneous injection of a $0.02 \mathrm{ml}$ solution of $20 \mathrm{mg} / \mathrm{kg}$ ketamine. The response of animals during surgery was monitored to ensure adequate depth of anesthesia. Animals were housed in a barrier facility on a high-efficiency particulate arrestance-filtered rack under standard conditions of 12-h light/dark cycles. Mice were fed with an autoclaved laboratory rodent diet.

Malignant lymphoma metastasis model. Four C57B/6-GFP transgenic mice (8-10 weeks old) were used as hosts. EL4 lymphoma cells were harvested by trypsinization and washed three times with cold serum-free medium, then resuspended in serum-free RPMI 1640 medium. EL4 cells $\left(2.0 \times 10^{6}\right)$ were injected into the spleen of mice. Three weeks later all the mice were sacrificed; all were found to have primary tumors as well as metastases.

CTC collection and culture. Blood $(0.2 \mathrm{ml})$ was obtained from C57B/6-GFP mice by cardiac and portal puncture 3 weeks after the injection of EL4 lymphoma cells. A drop of blood was smeared onto a glass slide and covered with cover glass. CTCs were detected by confocal microscopy. In case RFP-expressing EL4 lymphoma cells were observed, we defined these cells as CTCs and counted the number of CTCs. Cluster of RFPexpressing tumor cells with GFP-expressing host cells like blood cells or fibroblasts were defined as heterotypic CTC clusters. CTC clusters composed of only tumor cells were defined as homotypic CTC clusters. These CTCs were cultured on a plastic dish in the same condition as EL4 cells.

Tumor imaging. An SZX microscope and FV1000 confocal microscope (both from Olympus Corp. Tokyo, Japan) were used for imaging every day for a week.

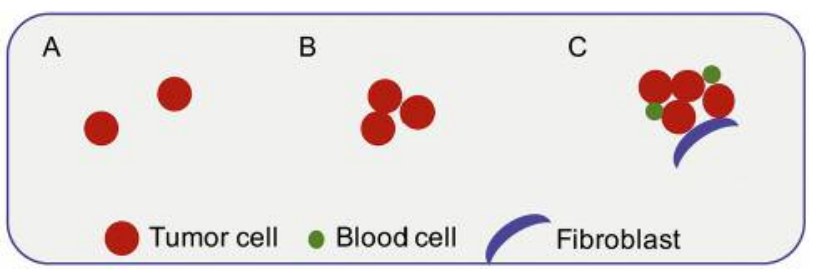

Figure 2. Schema of circulating tumor cells (CTCs) and CTC clusters. A: Single CTCs. B: Homotypic CTC cluster. C: Heterotypic CTC cluster. Multiple CTCs, blood cells, and fibroblasts were clustered together.

Table I. CTC counts from heart blood and portal blood. The number of red fluorescent protein (RFP)-expressing cells (CTCs) and total green fluorescent protein (GFP) -expressing cells in $0.2 \mathrm{ml}$ blood from heart or portal circulation of EL4 lymphoma-bearing mice is shown.

\begin{tabular}{lcc}
\hline Blood source & \multicolumn{2}{c}{ Number of cells $\left(\times 10^{4}\right.$ cell $/ 0.2 \mathrm{ml}$ blood $)$} \\
\cline { 2 - 3 } & CTCs & GFP expressing \\
\hline Heart & 39 & 11388 \\
Heart & 16 & 8032 \\
Portal & 25 & 14816 \\
Portal & 29 & 11772 \\
\hline
\end{tabular}

\section{Results and Discussion}

RFP-expressing EL4 lymphoma cells were injected into the spleen of transgenic C57B/6-GFP mice. Three weeks later, laparotomy was performed to obtain portal blood. Heart blood was obtained by cardiac puncture. Blood (0.2 

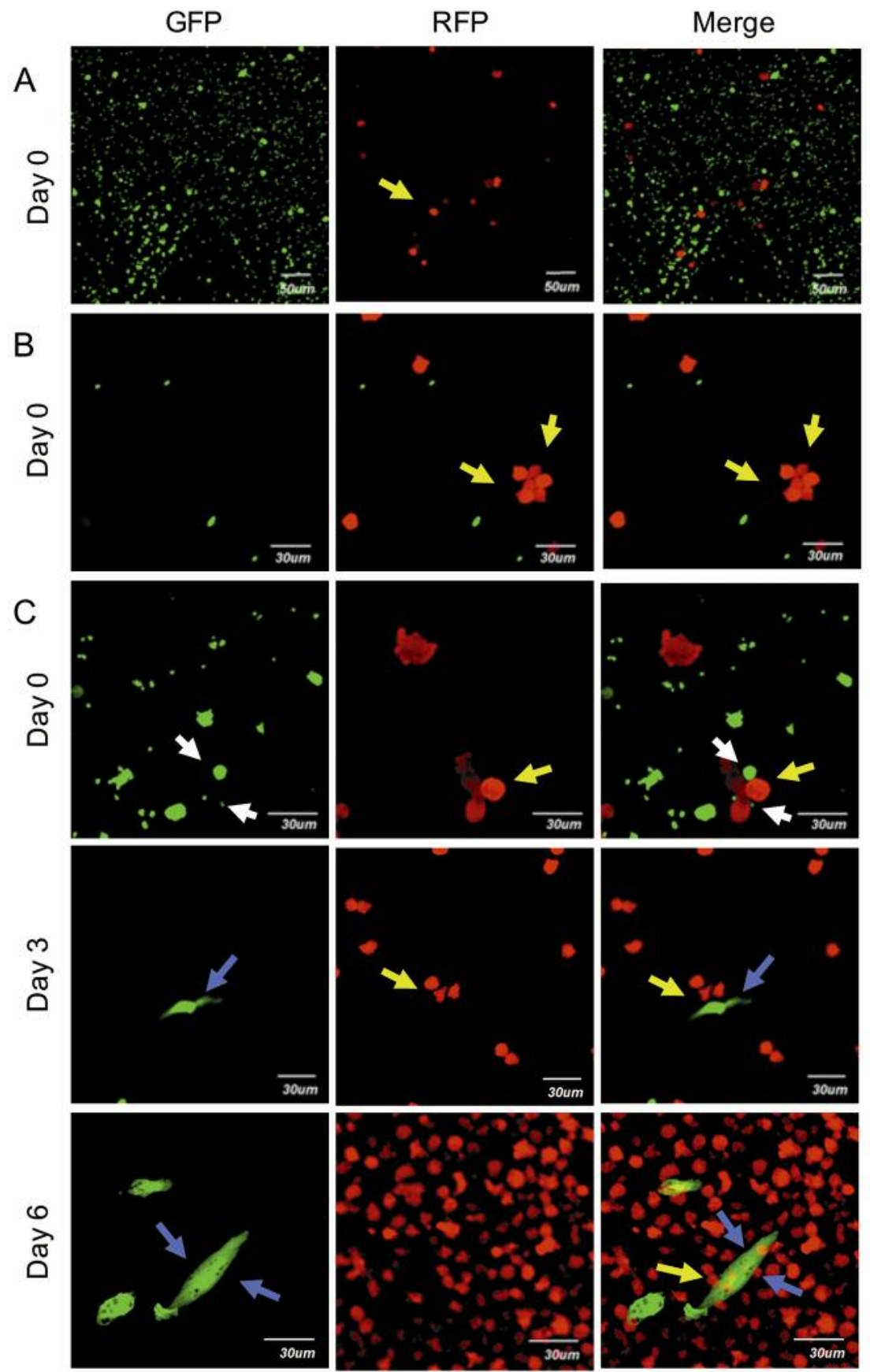

Figure 3. Representative images of circulating tumor cells (CTCs) and CTC clusters. A: Low-magnification images of single CTCs with green fluorescent protein (GFP)-expressing blood cells. Yellow arrow indicates a red fluorescent protein (RFP) expressing EL4 lymphoma cell. B: Highmagnification images of homotypic CTC clusters (yellow arrows). C: High-magnification images of heterotypic CTC clusters. Yellow arrows indicate EL4 tumor cells. White arrows indicate blood cells. Blue arrows indicate fibroblasts.

$\mathrm{ml}$ ) was collected from both the portal circulation and heart. After mice were sacrificed, the primary tumor in the spleen and multiple metastases in the liver were observed (Figure 1).
CTCs and CTC clusters were visualized by fluorescence microscopy in smears on glass slides made shortly after sacrifice and were also cultured for several days. We classified CTCs into the following three groups: single 
CTCs, homotypic CTC clusters, and heterotypic CTC clusters that contained fibroblasts. CTCs expressing RFP and fibroblasts expressing GFP were identified by color-coded imaging (Figures 2 and 3).

The ratio of CTC clusters in this experiment was $8.8 \%$ of total CTCs (Table I). Fibroblasts associated with CTCs were observed only in portal blood, not in heart blood. In the EL4 model, metastases as well as ascites were observed in the liver and lymph nodes. Zheng et al. demonstrated fibroblasts in circulating blood from patients with metastatic breast cancer (14). In addition, Yun et al. showed that CTCs in patients with hepatocellular carcinoma correlated with lung metastasis and intrahepatic recurrence (4). Fibroblasts in the CTC microenvironment may enhance metastasis and determine organ-specific metastasis.

\section{Conclusion}

Color-coded imaging gives rise to the concept of the CME and its potential importance. Further experiments are required to elucidate the role of the CTC clusters, and especially fibroblasts in clusters, in the CTC microenvironment, and whether they are a target for treatment to prevent metastasis and whether they are a predictive biomarker for organ-specific metastasis.

\section{Acknowledgements}

This work was supported, in part, by Grant-in-Aid for Scientific Research (17K09457 to A.S) from the Ministry of Education, Science, Sports and Culture of Japan.

\section{References}

1 Hong Y, Fang $\mathrm{F}$ and Zhang Q: Circulating tumor cell clusters: What we know and what we expect (Review). Int J Oncol 49: 2206-2216, 2016.

2 Sarkozy C, Baseggio L, Feugier P, Callet-Bauchu E, Karlin L, Seymour JF, Lebras L, Michallet AS, Offner F, Dumas O, Traverse-Glehen A, Ffrench M, Lopez-Guillermo A, Berger F, Coiffier B, Felman P and Salles G: Peripheral blood involvement in patients with follicular lymphoma: A rare disease manifestation associated with poor prognosis. Br J Haematol 164: 659-667, 2014.

3 Sun Y, Guo W, Xu Y, Shi Y-H, Gong Z, Ji Y, Du M, Zhang X, Hu B, Huang A, Chen GG, Lai PBS, Cao Y, Qiu S-J, Zhou J, Yang X-R and Fan J: Circulating tumors cells from different vascular sites exhibit spatial heterogeneity in epithelial and mesenchymal composition and distinct clinical significance in hepatocellular carcinoma. Clin Cancer Res 24: 547-559, 2017.

4 Watanabe S: The metastasizability of tumor cells. Cancer 7: 215223,1954

5 Aceto N, Bardia A, Miyamoto DT, Donaldson MC, Wittner BS, Spencer JA, Yu M, Pely A, Engstrom A, Zhu H, Brannigan BW, Kapur R, Stott SL, Shioda T, Ramaswamy S, Ting DT, Lin CP, Toner M, Haber DA and Maheswaran S: Circulating tumor cell clusters are oligoclonal precursors of breast cancer metastasis. Cell 158: 1110-1122, 2014.
6 Cho EH, Wendel M, Luttgen M, Yoshioka C, Marrinucci D, Lazar D, Schram E, Nieva J, Bazhenova L, Morgan A, Ko AH, Korn WM, Kolatkar A, Bethel K and Kuhn P: Characterization of circulating tumor cell aggregates identified in patients with epithelial tumors. Phys Biol 9: 016001, 2012.

7 Hou J-M, Krebs MG, Lancashire L, Sloane R, Backen A, Swain RK, Priest LJC, Greystoke A, Zhou C, Morris K, Ward T, Blackhall FH and Dive C: Clinical significance and molecular characteristics of circulating tumor cells and circulating tumor microemboli in patients with small-cell lung cancer. J Clin Oncol 30: 525-532, 2012.

8 Paoletti C, Li Y, Muñiz MC, Kidwell KM, Aung K, Thomas DG, Brown ME, Abramson VG, Irvin WJ, Lin NU, Liu MC, Nanda R, Nangia JR, Storniolo AM, Traina TA, Vaklavas C, Van Poznak CH, Wolff AC, Forero-Torres A, Hayes DF and Translational Breast Cancer Research Consortium (TBCRC): Significance of circulating tumor cells in metastatic triplenegative breast cancer patients within a randomized, phase II trial: TBCRC 019. Clin Cancer Res 21: 2771-2779, 2015.

9 Liu MC, Shields PG, Warren RD, Cohen P, Wilkinson M, Ottaviano YL, Rao SB, Eng-Wong J, Seillier-Moiseiwitsch F, Noone A-M and Isaacs C: Circulating tumor cells: a useful predictor of treatment efficacy in metastatic breast cancer. J Clin Oncol 27: 5153-5159, 2009.

$10 \mathrm{Mu}$ Z, Wang C, Ye Z, Austin L, Civan J, Hyslop T, Palazzo JP, Jaslow R, Li B, Myers RE, Jiang J, Xing J, Yang $H$ and Cristofanilli M: Prospective assessment of the prognostic value of circulating tumor cells and their clusters in patients with advanced-stage breast cancer. Breast Cancer Res Treat 154: 563$571,2015$.

11 Molnar B, Floro L, Sipos F, Toth B, Sreter L and Tulassay Z: Elevation in peripheral blood circulating tumor cell number correlates with macroscopic progression in UICC stage IV colorectal cancer patients. Dis Markers 24: 141-150, 2008.

12 Chang M-C, Chang Y-T, Chen J-Y, Jeng Y-M, Yang C-Y, Tien Y-W, Yang S-H, Chen H-L, Liang T-Y, Wang C-F, Lee EYHP, Chang Y-C and Lee W-H: Clinical significance of circulating tumor microemboli as a prognostic marker in patients with pancreatic ductal adenocarcinoma. Clin Chem 62: 505-513, 2016.

13 Matsumoto T, Suetsugu A, Hasegawa K, Nakamura M, Aoki H, Kunisada T, Tsurumi H, Shimizu M and Hoffman RM: Colorcoded imaging of syngeneic orthotopic malignant lymphoma interacting with host stromal cells during metastasis. Anticancer Res 36: 1473-1478, 2016.

14 Ao Z, Shah SH, Machlin LM, Parajuli R, Miller PC, Rawal S, Williams AJ, Cote RJ, Lippman ME, Datar RH and El-Ashry D: Identification of cancer-associated fibroblasts in circulating blood from patients with metastatic breast cancer. Cancer Res 75: 4681-4687, 2015.

15 Nakamura M, Suetsugu A, Hasegawa K, Matsumoto T, Aoki H, Kunisada T, Shimizu M, Saji S, Moriwaki H and Hoffman RM: Choline-deficient-diet-induced fatty liver is a metastasis-resistant microenvironment. Anticancer Res 37: 3429-3434, 2017.

Received June 26, 2018

Revised August 26, 2018 Accepted August 27, 2018 